\title{
A Research of Ecological Civilization Construction in the Resource-exhausted City: An analysis of Tangshan South Lake Wetland Ecotope
}

\author{
Fu Lei ${ }^{1}$ Yan Xiong ${ }^{2}$ * \\ ( ${ }^{1,2}$ In Yunnan University of Finance and Economics. Kunming. China ) \\ (E-mail: yxiongemail@163.com)
}

\begin{abstract}
In order to achieve the coordination and mutual development between human and nature, ecological construction, as one of the inevitable stages in the social development of civilization, whose substance is to respect and protect the natural criterion and the ecological environment order, puts emphasis on social and ecological system of the overall interests. By means of relying on the local environment foundation, South Lake Wetland Ecotope in Tangshan, one of resource exhausted cities illustrates the transformation from coal mining subsidence area and garbage accumulation zone to an ecological civilization construction of circulating development in microcosm, which has important reference meanings for the region in the development of ecological civilization construction.
\end{abstract}

Keywords: Resource-Exhausted City, Ecological Civilization, Tangshan South Lake Wetland Ecotope

\section{Introduction}

Ecological civilization, as one of important connotations of culture, is not only the need of the cultural development in the era, but also an important part of regional development. Ecological civilization is an interaction relationship and state of being between lives as well as lives and environment, which is also called as natural ecological state. In the process of regional development, ecological civilization is not only the total of material and spiritual achievement, as the result of the objective laws about human and natural social harmonious development, which followed by human, but also contains the relationships between human and human, human and nature, human and society, which are the cultural ecological form, aimed at to be harmonious coexistence, virtuous cycles, integrated developments and continuous prosperity. With the help of ecological civilization construction, resource exhausted city gradually realizes a change from unitary type consumption of resource to the sustainable economic harmonious development with environment.

\section{Development of Exhausted Resource City Needs the Concept of Ecological Civilization Urgently}

Cities with exhausted resources is cities of which mineral resources develop into a recession or dry process, and also called resources type city recession, whose characteristics such as are single industrial structure, not having formed alternative industry, low per capita living level and low sensitivity of ecological civilization construction.

In the long history of Chinese civilization, the concept of ecological civilization was grounding in Chinese traditional culture of the Chinese nation, and lived with in the constant development and expansion of the years.

For the purpose of "nature and humanity", the Confucian school ecological wisdom is the core of moral, intellect and acknowledgement of nature. Thinking the intrinsic value can be confirmed through the universe and human, Confucian school advocates to treating nature in a love heart, and sometimes, the fear to nature are basic necessarily. The Confucian ecological ethics largely reflects a kind of tolerance of the pursuit to ideal harmonious society.

Regarding the regular patterns of nature and earth as the basic life's behavior conviction, Chinese Taoist ecological wisdom is a kind of pursuit of naturalistic wisdom, which advocates perfecting and improving self-life in the fear of 
nature. Furthermore, it is also an intrinsic consistency between consciousness of modern civilization about human and environment friendly, and the ecological civilization concept.

Chinese Buddhist ecological wisdom core is loving everything in the pursuit of liberation, which inspires people to aspire lives, in the process of transform about purification in life experience. Through the relationship between human and nature in harmony of showing compassion for the fruit of the spirit of ecological ethics, it is origin that people realize personal value without hurt others.

Through the simple analysis of the Chinese traditional thought of Confucian, Taoist and Buddhist thoughts about the concept of ecological civilization, it is not difficult to discover that, the fear of nature, the harmony between human and nature and the cherishing of the natural life can be traced back to the Chinese traditional ecological civilization in the history of the development. However, in the era of the development of today, how to outstand traditional ecological civilization concept in development of resource-exhausted city becomes the key to progress, in which whether economic, cultural and other aspects of resource-exhausted city can be harmonious, at a high speed, or in high efficiency.

\section{Pattern Analysis of Tangshan South Lake Ecological Wetland Ecotope Construction}

3.1 Tangshan, located in the center of the Bohai sea gulf, adjacent to Beijing and Tianjin, in China, covers an area of 13472 square kilometers and a population of 7.145 million, which is one of cities with exhausted natural resources in China. As a typical resources city, with the 1976 Tangshan earthquake, the urban area in Tangshan damaged into ruins. After the earthquake, through the national governments at all levels and people's help from all parts of country, the district reconstruction work has been a huge success. However, due to the limitation of being a resource-exhausted city and a model mainly of coal industry in heavy industry, regional inhabitation environment is poor. Thus, since the ninety's, Tangshan has made a plan to be an ecological civilized city throughout a transformation.

3.2 Tangshan South Lake Ecotope, located in Tangshan city, was a piece of coal mining subsidence area. It is a long exploration process about how to deal with the transformation about this coal mining subsidence. At last, the transformation about a project of urban wetland park was the final choice, with possibly many other kinds of management approaches, such as, cultivated land reclamation, construction land, and agricultural facilities and so on.

3.2.1 Step1: free-pollution disposal waste mountain. For the purpose of clearing more than twenty meters high junk mountain, Tangshan managed to mound hills in the garbage east side--north and south long 80 meters, 10 meters high, like a retaining wall. Then, good soil covered $80 \sim 100$ centimeters above, with soil twenty centimeters deeper in the mountain surface, becomes foundation soil for plants' growth. What's more, many kinds of plants are grown on the soil in the surface of hills.

3.2.2 Step 2: Landfill waste pool. Waste pool is one of the main pollution sources, because of coal mining subsidence formation water pit. First of all, block drain, and landfill sewage pipe network of more than 5300 meters. Secondly, build sewage tank to realize sewage fractional precipitation. Thirdly, getting the original divisible sumps together to be a whole big lake by thrilling sumps, so that the fish and plants that can be hidden in the deep water area and the central lake without human interference factors. After the transformation, species in the lake obviously increased, especially the number of wild duck rises from initial ten to the current scale of more than 600. In addition, there are large areas of sinking abandoned pool in the coal mining subsidence area, which was covered with planted soil. As a result, a large scale of soil model a series of ups and downs, abound the changing terrain.

3.2.3 Step 3: A good ecological system is formed by a large number of plant trees, shrubs and herbs, with all kinds of insects, birds and other animals introduced. Taking advantage of the dam of original pond and a small island, whose building area is 2000 square meters in the center of lake. What's more 5000 square meters of lotus, can not only clean the lake, but also form a distinctive characteristics scenic spot of enjoying flowers.

3.2.4 Step 4: Considering the geological characteristics of settlements, South Lake Wetland Ecotope uses less heavy machinery, iron and steel, cement and asphalt, in addition to construct the pavilion, gallery, bridge and marinas, so that to keep rest space as large as possible for the wild birds and other animals. At present, there are more than 2 million plant trees, green area of 607 hectares, lake-wetland and square kilometers in the lake, with more than forty kinds of plants and thirty kinds of fish.

In brief, South Lake Wetland Ecotope, covering an area of 105 square kilometers, whose main part have been accomplished by 2010,includes five areas, such as the core scenic area, northwest area, Fengnan area and so on. The ecological reconstruction project has been 
finished through the completion of the expansion with lake landscape greening, conducting the earthquake park, greening the garbage mountain and a number of ecological reconstruction methods in the past two years. Nowadays, with urban highest and lowest temperature lower and higher 3 to 4 degrees Celsius throughout the year, this ecological center city park is improving regional climate and ecological environment of urban in Tangshan as a huge city "green lung”. Because of attracting millions of tourists and a hot investment and business coming, the price of surrounding area land rises from 10 thousand Yuan to more than 200 thousand Yuan per unit area, which leads to value more than 1000 billion Yuan. Due to the contribution in improving living environment, South Lake Wetland Park has won the "China Habitat environment model prize", the "Dubai International Award for best practices to improve the living environment" from the United Nations, the "HBA China Outstanding Contribution Award for best example” from the United Nations Environment Programme (un-habitat) and the "national ecological demonstration base" (the national honor only two in China).

\section{Reasonable way to Development of Resource-Exhausted City in the Construction of Ecological Civilization.}

4.1 Ecological civilization construction and economic progress should supplement each other, and make progress together. In ecological civilization construction of Tangshan area, we can see, development of resource-exhausted citiy will be seriously impeded, as the result of ecological environment consequences once accumulated. So, there are a lot of disadvantages to take environment for the development of urban construction.

In the new era of global development of fierce competition between regions, we need to look for a way, not only of how to get rich quickly, but how to step into for sustainable and comprehensive progress. Ecological civilization construction is the goal and direction of regional development in the future, as well as the destination of a healthy happy life for the area residents.

4.2 Development of resource-exhausted city and ecological environment realize benign mutual. With the local environment conditions as the basis, ecological civilization development can realize sustainable development via a series of adjusting measures, with the aid of geographical factors and area elements.
Therefore, ecological construction should be paid attention to not only the relationship with economy and advantage guidance itself in development of the resource-exhausted city, but the need to area residents in cities.

In a word, it is factors of local conditions of historical and cultural characteristics, development direction of environment, local residents' living habits that are the true benign mutual for ecological civilization to suit regional development.

4.3 Promote elements in regional ecological civilization construction to develop harmoniously. In the process of regional development, any ecological elements, such as human, nature and society, are not independent with each other, and they can fuse with the surrounding area to reach a situation of coordination and unity. In addition, comprehensive coordinated planning is needed to distribute the input to ecological civilization of human resources, capital and other material elements.

In the process of ecological civilization construction of resource-exhausted city, incompatibilities of ecological civilization construction hinder the economic development to some extent. Therefore, the relationship between resource and ecological civilization has a great influence to whether ecological civilization construction can realize a benign operation.

4.4 Construct a benign capital circulation chain of citizen, enterprise, local ecological civilization and government. At present, as the shortage of economic development power and a weak economic foundation structure, the shortage of the funds to conduct ecological civilization construction is the main "bottleneck". Then, it is necessary to rely on the government as a regulatory body, and absorb social funds for construction via investment promotion. How to recover the fund feedback to society and infrastructure is the key to keep ecological civilization in long-run development. It is public investment that connects the local governments and market economy, who can undertake area ecological civilization construction and management, which is worth advocating. Nevertheless, it is also because the market intervention, some market failure and invalid government are inevitably.

\section{Conclusions}

Ecological civilization construction has to consider not only the requirements of the regional economic and cultural aspects in the development, also consider the practical need to area residents. More attention should be paid to 
the ecological civilization construction and the relationship between the local natural environments. Due to the shortage problem of congenital economic development, managing the ecological civilization construction and inevitable to every resource-exhausted city in the global economic development trend, but the key to achieve multi-level and higher-level development from single economic resource industry to sustainable green economy. Only by carefully anglicizing of the local natural environment, human and geography factors, can guarantee that construction of ecological civilization with local industry are in good compatibility, which makes the ecological civilization construction to realize the real meaning of great-leap-forward development.

At last, strengthen the construction of ecological civilization, is the key to realize resource-exhausted city's economic prosperity, and really get human and the nature harmonious, getting along with economic and social healthy, and coordinated and sustainable development of modern civilization.

\section{References}

[1] Zheng. Yan, “China's Urban Development Report”, China’s development press, pp.112-159, 2004.

[2] Xiao. Yun, "Urban Infrastructure Investment and Management”, Fudan University Press, pp.1-3, 2004.

[3] Yong. Wu, Jianqing. Wang, Sustainable Operation Management of Water and Garbage Disposal Facilities in Netherlands and Other European Major Countries, China Architecture \& Building Press, pp.42-45,192-196,2008.

[4] Yun. Zhang, Research in Ecological City Construction of Urbanization and Ecological Perspect, Physical Geography, 2005.

[5] China Real Estate Information Corp, G and red (China) information technology co, Expo Best City Practice Area Sample Research-2020 City Life in the Future World, Dalian University of Technology Press, pp.132-137, 2011.

[6] Tangshan Government Work Report in 2010, URL: http:/www.tangshan.gov. cn/html/xinxigongkai/gzbz/2010/0427/ 391.shtml.

[7] Tangshan Government Work Report in 2011, URL: http:/www.tangshan.gov. cn/html/xinxigongkai/gzbz/2011/0805/ 31474.shtml.
[8] Tangshan South Lake Eco-city Website: http://tssouthlake.gov.cn/ghzl/index. shtml. 